\title{
América, ¿continente de la esperanza? Una respuesta desde la perspectiva de Clarence Finlayson
}

\author{
America, continent of hope? A response from \\ the perspective of Clarence Finlayson
}

América: ¿é o continente da esperança? Uma resposta a partir da perspectiva de Clarence Finlayson

Fecha de entrega: 10 de diciembre de 2013 Fecha de evaluación: 10 de febrero de 2014

Fecha de aprobación: 16 de marzo de 2014

Hugo Ochoa Disselkoe

\section{Resumen}

Para Finlayson, el descubrimiento de América constituyó el fin de un ciclo, la circunvalación del globo, el encuentro de las dos corrientes migratorias que, habiendo partido de Asia, se dirigieron una hacia el este y la otra hacia el oeste. Frente a la Europa de ese entonces, acosada por cruentas guerras religiosas, desunida, amenazada por el oriente, integrada por muchas naciones que aún no eran propiamente Estados,

* Doctor en Filosofía de la Universidad de Navarra en España. Profesor de la Universidad Católica de Valparaíso. Sus temas de trabajo filosófico son la epistemología, la hermenéutica textual y la filosofía de la naturaleza. Ha desarrollado amplias investigaciones sobre la libertad, la educación, Santo Tomás y Heidegger. Correo electrónico: rochoa@ucv.cl Este trabajo corresponde al proyecto de investigación FONDECYT 1114032. 
con la legitimidad de los gobiernos en una crisis que ya se preveía, América aparecía como territorio de esperanzas. Tal situación es, en algún sentido, análoga a la que se vivió en los años cuarenta del siglo $\mathrm{XX}$, y así sostiene Finlayson: “[...] la superpoblación, los conflictos internacionales, la pobreza, las guerras que hoy asuelan casi todo el mundo tienen su esperanza concreta en los inmensos territorios de América”. No obstante, parece que se trata de una esperanza siempre incumplida y siempre postergada.

Palabras clave: América, Finlayson, filosofía latinoamericana.

\section{Abstract}

Finlayson thinks that the discovery of the Americas is the end of a cycle, the circumnavigation of the world, the convergence of two migratory flows that having departed from Asia, one went to the east and the other one went to the west. In relationship with Europe, beset, at those times, by bloody religious wars, disunited, threatened by the East, made up by many nations that were not States just yet, with the legitimacy of the governments in an already foreseen crisis, the Americas look as a land of hope. Such a situation is, somehow, similar to the situation undergone by the period of the 40 's, in the 20th Century, and thus Finlayson says so: "the overpopulation, the international conflicts, the poverty, the wars devastating almost the entire world put their trust on the vast territories in the Americas." Nonetheless, this seems to be a hope that has never been fulfilled and that has always been postponed.

Keywords: Americas, Finlayson, Latin American philosophy. 


\section{Resumo}

Para Finlayson, a descoberta da América, marcou o fim de um ciclo, a circum-navegação do globo, a reunião dos dois fluxos migratórios que, tendo iniciado na Ásia, dirigieram-se uma para o leste e a outra para o oeste. De frente para a Europa de essa época, assolada por guerras religiosas sangrentas, desunida, ameaçada pelo Oriente, composto de muitas nações que não foram ainda devidamente Estados, com a legitimidade dos governos em uma crise que já era esperada, América apareceu como território de esperanças. Tal situação é, em certo sentido, análoga à vivida nos anos quarenta do século XX, diz-se Finlayson: “[...] a superpopulação, os conflitos internacionais, a pobreza, as guerras que assolam hoje a quase todo o mundo têm a sua esperança concreta nos vastos territórios da América”. No entanto, parece que se trata de uma esperança sempre incumprida e sempre adiada.

Palavras-chave: América, Finlayson, filosofía latino-americana. 


\section{Introducción}

Para Clarence Finlayson, el descubrimiento de América significó una suerte de cumplimiento de un destino, el término de una travesía que se había iniciado en los mismos albores de lo humano. En efecto, sostiene:

Las dos grandes corrientes migratorias que, según los visos más acertados, habían partido de Asia, una en dirección hacia el Oriente y la otra hacia donde el sol se pone, se encuentran oficialmente en el Continente americano. Se había circunvalado el globo en función del hombre. Y es aquí en América donde tiene lugar el nacimiento de una nueva raza, la que hoy se ofrece como esperanza virgen al mundo, de cruzamiento del peninsular con el indígena. (Finlayson, 1948, p. 407)

Efectivamente, este encuentro abraza al planeta y describe, más que un encuentro, un reencuentro, constituyéndose propiamente en el orbe como una forma de toma de posesión definitiva. A partir de ese momento, no solo en América, sino que en todo el orbe, cambia radicalmente la perspectiva acerca del destino humano: ya no se tratará de conquistar, sino de colonizar. Tradicionalmente, la fuente primaria de los bienes y de la dignidad es el derecho que surge de una conquista, pero, por eso mismo, la distancia entre conquistador y conquistado es irremontable. La conquista se juega en la victoria, su objeto es el botín, pretende la aniquilación del enemigo, y el conquistador siempre se siente nativo de su patria original, porque la poca seguridad que se pueda alcanzar está siempre al interior de las fronteras construidas por una estirpe que, en general, aborrece de mezclas y que, así como trata de conservar el territorio, trata también de conservar su línea de legitimidad. No obstante, la conquista de la América hispánica se convierte inmediatamente en colonización, es decir, el conquistador, al fijar en América su morada, hace tanto de la tierra como de los indígenas un área de cultivo en la que planta su simiente. De allí que, según Finlayson:

El descubrimiento de América señala una etapa biológica, no un simple hecho histórico. Las corrientes migratorias: una, la que fue a mirar donde el sol salía; la otra, que más civilizada en aquel momento hallábase detenida ante las costas del Atlántico, terminan su circunvalación y de una manera oficial circundan el planeta. Si españoles e indígenas americanos hubieran conocido bien sus ancestrales orígenes, sus milenarias procedencias, habrían hablado el 
lenguaje universal de la aventura étnica y humana más populosa y caudalosa de la existencia humana en su sentido dinámico y biológico por subsistir y por aventurar. (Finlayson, 1953b, p. 133)

Por eso, una vez que se ha cerrado el ciclo, que se han encontrado los dos itinerarios de la marcha humana, se abre la posibilidad de una nueva etapa, en la cual, habiendo desaparecido la terra incognita, el mismo ser humano se convierte para sí en la frontera de un nuevo territorio por conquistar. De este modo, no es raro, según Finlayson, que la fundación del derecho internacional moderno por Francisco de Vitoria haya tenido lugar a propósito de la conquista de América:

La obra de Vitoria nos indicó los principios y los rumbos espirituales a seguir, la dignidad de la persona humana y la fundamentación de los derechos individuales y de las naciones. Relectiones de indis [1532] y De bello jure ac pacis, obras nacidas al calor y al contacto de América, plantaron la semilla del ulterior derecho internacional. (Finlayson, 1948, p. 408)

Así pues, este habría permitido la conformación del concepto de humanidad como tal, que está a la base de la obra de Vitoria. Ya no se trata de "estos" y "aquellos" o de "nosotros" y "ellos", sino de una comunidad también de naturaleza política; tampoco se trata meramente de una declaración que reconoce una igual filiación originaria, en cuanto hijos de un mismo Padre, sino de derechos meramente humanos que, como tales, son comunes y compartidos. Naturalmente, la implementación y puesta en práctica de todo esto tiene enormes dificultades, pero con Vitoria quedaba marcado definitivamente un rumbo y un sentido. De este modo, la llegada a América de los pueblos europeos significó una oportunidad de que este reencuentro fuera no solo territorial, sino, como lo señala Finlayson, biológico y espiritual, en el que el mutuo reconocimiento fundara un modo de habitar que trascienda la conquista misma en un mestizaje de raza, cultura y vida. No es de extrañar, pues, que

[...] Francisco López de Gómara (1510-1560) Capellán de Cortés en España, y autor de Hispania Victrix o Historia General de las Indias y conquista de México, obra que aparece en la edición de Zaragoza en 1552, dividida en dos partes, ha escrito esta frase famosa dirigida a Carlos V. Ella reza así: 'La mayor cosa después de la creación del mundo, sacando la encarnación y la muerte del 
que lo crió, es el descubrimiento de las Indias; y así las llaman Mundo Nuevo’.

(Finlayson, 1948, p. 413)

El solo hecho de que América se muestre entonces como un "mundo nuevo" pone en evidencia que Europa se vea a sí misma como un mundo viejo, acosada por cruentas guerras religiosas, desunida, amenazada por el Oriente, con naciones envueltas en continuos conflictos de poder y primacía y en la que en crisis la percepción del sentido de la vida humana. "Ambas Américas, la latina y la sajona, nacieron religiosamente a la escena con una posición de lucha: recibíamos a Europa en los momentos en que se partía en las más hondas raíces" (Finlayson, 1945a, pp. 90-91). Dado lo anterior, América aparece como esperanza, no solo para aventureros, marginados o perseguidos, sino también para Europa misma, como oportunidad de obtener un nuevo sentido histórico. Así habría efectivamente ocurrido, y esto no solo por el oro y el comercio a que dio lugar el descubrimiento de América, sino sobre todo porque a partir de aquí la cultura europea comenzó a concebirse a sí misma, con razón o sin ella, como propiamente universal, como portadora y depositaria de una forma de ser y obrar, de vivir y morir, cuyas verdaderas fronteras son, desde esta perspectiva, la superstición, el error y el fanatismo. La independencia de América, tanto la de la española como la de la sajona, sigue ese precepto, es solo mucho más tarde que se redescubre lo que llama Finlayson las raíces “afroindoeuropeas" de nuestra América. No obstante, las guerras de independencia afianzaron al ejército como el único cuerpo organizado y capaz de ordenar y dirigir países carentes de infraestructura y pueblos estratificados cultural, racial y económicamente. De esta manera, la esperanza de lograr una unidad que trascendiera los límites geográficos, que significó originalmente América, se perdió en luchas intestinas y en la disputa por el poder.

\section{II}

Clarence Finlayson nace en Valparaíso en 1913 y muere trágica y misteriosamente en Santiago en 1954; es espectador, por lo tanto, de la Segunda Guerra Mundial, que, dado su encadenamiento con la Primera, por una parte, y las dimensiones que había adquirido la técnica de eliminar masivamente a seres humanos, por otra, hacía que Europa pareciera un continente que definitivamente, esa vez sí, se dirigía raudamente a su declinación y envilecimiento. Es necesario tener presente la imagen de una Europa desolada, devastada, en la que campeaba el hambre, la escasez, la enfermedad 
y la muerte, el odio y el resentimiento. ¡Cómo no pensar que la esperanza de una rehumanización está en América! Esta no es solo la opinión de Finlayson. En una recensión a "Descubrimiento de América” de Waldo Frank, Finlayson comenta:

En esta obra, aparecida en momento oportuno, sostiene el autor la necesidad para América de autodescubrirse, especialmente en los instantes en que el viejo mundo de Europa se está destruyendo. [...] No embargante, la lentitud del proceso histórico nuestro nos permite elaborar más profundamente formas culturales y autóctonas, asimilamos con más visión cósmica los grandes problemas e interrogantes mundiales. (Finlayson, 1943, pp. 453-454)

La lentitud característica de América no significa un lastre que la obligue a ir a la zaga, sino que ahora, por el contrario, al contemplar desde el borde de la guerra y de la destrucción lo que estas significan, le permitirá comprender a dónde conducen la carrera del poder, la presunta preeminencia racial o tecnológica, los conflictos económicos o políticos. La guerra mundial y los campos de concentración plantean una pregunta que no solo interroga por el futuro, sino por la condición humana. Si el terremoto de Portugal le permitió a Voltaire ironizar sobre el mejor de los mundos posibles, la Segunda Guerra Mundial (nótese que no es primera) pone en cuestión la misma posibilidad de lo humano. Parecía necesario, pues, un nuevo renacer.

Biológica e históricamente nuestra América es el mundo del porvenir. [...] El hombre americano entra en la nueva etapa histórica como el hombre nuevo, después de la muerte del hombre renacentista. Esta guerra [Segunda Guerra Mundial] tiene este valor revolucionario, revolucionario de destrucción y muerte, indicador de un mundo que para siempre desaparece de la escena de esta tierra, siempre en tránsito, siempre en peregrinación. (Finlayson, 1943, p. 454)

Una de las constantes del pensamiento de Finlayson, expresado de múltiples maneras, es que al movimiento anagenésico, de desarrollo y crecimiento, sigue inevitablemente otro katagenésico de destrucción, aniquilamiento y muerte, y esto afecta también a las naciones entendidas como procesos históricos.

Los sistemas llegan cuando el proceso histórico está en su algidez, en su clímax. Una vez producidos y efectuados en toda su perfilidad, el movimiento de la historia se procliviza y declina y no termina sino en la muerte, salvo que 
conduzca ciertos valores esenciales que de suyo son siempre extratemporales y eternos. Pero, como expresión simplemente histórica — que es lo que ahora nos interesa-constituyen un fenómeno del tiempo, es decir, un evento precésico. (Finlayson, 1945a, p. 95)

De modo que parecía que el viejo mundo, de tan viejo, finalmente agonizaba, y lo hacía en un desgarro en el que iba destruyendo su historia, sus monumentos, y asesinaba o perseguía a sus sabios, poetas y filósofos. Por el contrario:

[...] el mundo americano abre sus brazos a la humanidad de otras naciones. La superpoblación, los conflictos internacionales, la pobreza, las guerras que hoy asuelan casi todo el mundo tienen su esperanza concreta en los inmensos territorios de América, lejanamente extraños y al mismo tiempo hondamente íntimos y acogedores. (Finlayson, 1945a, p. 99)

América resurge, pues, como el mundo de la esperanza: es refugio, pero también es espacio abierto e inmenso para cultivar y cultivarse; carece de un pasado, pero tiene todo el futuro ante sí; es extraña, agreste, pero acogedora e íntima. Por esto, Finlayson está en ese momento convencido de que "nuestra América Hispana se ofrece hoy al mundo como un continente de esperanza. No hay duda alguna, cuando observamos los múltiples y distintos aspectos de la época, que un día no muy lejano hará oír su voz universal” (Finlayson, 1953a, p. 124). América es el lugar donde las distintas razas se han encontrado tras, como decíamos, el largo periplo que se inició con la aparición del ser humano. América es de suyo universal en cuanto punto de encuentro, solo le falta una voz, o un coro de voces, que ya no siembre sobre lo ya sembrado (Finlayson, 1945a, p. 95), sino que cultive su propio espíritu enraizado en la tierra que le da la vida. La situación de Europa era de tal desmantelamiento de lo que habían sido sus riquezas, sus logros, su cultura y los principios originales que la habían fundado, que parecía haberse iniciado su declive definitivo, como parecía no poder ser de otra manera luego de las dos devastadoras guerras en las que se había visto envuelta. Pero no se trata solo de la destrucción que las guerras han causado, sino de algo más profundo y, por esto, aparentemente definitivo: las ideologías destructivas que han dado lugar al desastre constituyen un desenlace aparentemente final, porque tocan a la concepción que tiene el ser humano de sí mismo, del mundo y de Dios. No se trata solo del nazismo, fascismo o comunismo, sino que a Finlayson 
le parece que una oscura tendencia autodestructiva, que había comenzado mucho antes, está llegando a su última fase, en la que todo aparece mezclado en un galimatías incoherente de doctrinas, ideologías y explicaciones principistas, que le parecen, todas ellas, fragmentarias, unilaterales y reduccionistas.

El Dios-Idea de Descartes, el Estado omnipotente de Hobbes y de Hitler, el hombre natural y solitario de Rousseau, el hombre económico de Marx, el último peldaño del animal evolucionado de Darwin, el hombre-poder de Maquiavelo, el superhombre de Nietzsche, el ario soberbio de Rosenberg, el hombre máquina del capitalismo, la Humanidad-Dios de Comte, el hombre 'líbido' de Freud, el hombre 'dionisíaco' de Klages, el hombre 'comida' de Feuerbach, el ateo morboso de Moleschot, el dios-Mammón del burgués moderno, el dios-fantasma del pecador empedernido, el homo faber del positivismo, el libre existencialista de Sartre, el hombre angustiado de Kierkegaard, el hombre violento de Sorel, el 'producto social' de Durkheim, el 'resultado glandular' de la Endocrinología, el primum movens de Schopenhauer, el hombre como 'enfermedad de la vida' de Alsberg, todos, absolutamente todos se escuchan en las sombras 'comme de longs échos qui de loin se confondent. - En une ténébreuse et profonde ubité Vaste comme la Nuit et comme la ciarté- Les parfums, les couleurs et les sons se répondent [Correspondence, Baudelaire, Les fleurs du mal]. (Finlayson, 1950)

Para Finlayson, en todos estos, diríamos hoy, hay un aire de familia, convergen en una negación fundamental, el abandono del ser, lo que conduciría a una comprensión intrascendente del ser humano, como algo radicalmente superfluo, como un dispositivo viviente más, carente de toda dignidad constitutiva. De ahí que no se pueda, parecía, hacer radicar la esperanza en Europa, porque su devastación no es solo material y humana, sino que se puede rastrear a las filosofías allí vigentes, ya que esta, como disciplina esencial del ser humano (Finlayson, 2006), si bien constituye una articulación de sentido, también puede serlo de un sin sentido. Por el contrario, Finlayson cree percibir en América el inicio de un pensar que ya no es meramente imitación, sino que ahora es crítico:

En nuestras tierras de América surge hoy un movimiento que busca desesperadamente su expresión. Las tentativas sociológicas, los intentos filosóficos, los ensayos literarios son muestra de dichos anhelos. Todos ellos manifiestan un íntimo deseo de consciencia y reflexión. Cuando la madurez intelectual de un 
proceso histórico deviene a sus estaciones álgidas y climatéricas la tendencia pensante camina en derechura hacia el interior y hacia la crítica. Transcurrimos por un estadio de inicial madurez y sazón. (Finlayson, 1945a, p. 89)

Se estaría, pues, en un momento de transición hacia una madurez filosófica, es decir, hacia una verdadera autonomía e independencia de América, abandonando, en términos de Kant, su minoría de edad. Ahora bien, el motor fundamental que puede conducir a tal madurez no podría ser otro que la filosofía, no solo por su carácter de fundamento y articulador de una comprensión del mundo y de la vida, sino sobre todo porque, si se es fiel a su naturaleza, paradójicamente esta configura la trascendencia de lo humano.

Es de observar en nuestra América el inusitado interés que comienza por doquiera a surgir por las investigaciones filosóficas. Aparece este fenómeno por extraña y secreta coincidencia como una resurrección in extremis: ante el desplazamiento de los valores de Europa, ante la destrucción de la guerra, América se brinda como seguro y anhelante refugio del espíritu. Después del conflicto sin duda alguna, nuestro continente aflorará a la escena mundial ofreciendo su personalidad. (Finlayson, 1941, p. 329)

Finlayson es un permanente lector de las obras filosóficas latinoamericanas, viaja por América, mantiene contacto con los más importantes filósofos del momento, a muchos los conoce personalmente, comenta sus obras y, en muchos artículos, dialoga o discute con ellos; él mismo se siente también protagonista de este "resurgimiento del espíritu” (Sánchez de Irarrázabal, 1988, p. 116). No se trata, entonces, de una mera declaración de intenciones, o una simple aspiración académica (Hanisch, 1969). Por esto, disiente de Francisco Romero, quien afirma que una filosofía original en América sería casi un milagro. "Creo, contra la opinión de Francisco Romero, mi ilustre colega, que en América se creará pronto una filosofía de carácter mundial. Original quizá no en el desenvolvimiento de los principios, pero de contenidos universales" (Finlayson, 1941, p. 329).

Como sostiene Escobar (1956), “[...] la visión trascendental de Finlayson se dirigió al ser a través de agudos análisis artísticos los que le permitieron descubrir muchos aspectos de alma del mundo americano" (p. 338). Por esta razón, para Finlayson, es tal vez en la poesía americana, antes que en la filosofía, en la que está el claro eco 
de ese destino fundamental de América. La vena poética que fluye en los escritos de Finlayson hizo que Enrique Molina lo llamara "poeta de la metafísica” (1953, p. 70). No es raro, pues, que en un momento tan temprano como 1938, Finlayson mostraba cómo Pablo Neruda, a quien calificaba ya entonces como "[...] uno de los más grandes poetas de nuestra época”, en su poesía refleja “[...] la tierra de Chile y su tristeza prendida al alma” (Finlayson, 1938, p. 47). El paisaje, la tierra, la gente, su espíritu, el horizonte que lo circunda adquieren en su poesía, precisamente, un tinte universal, sin dejar de ser absolutamente local. "Neruda en sus más lejanas producciones, en temas los más universales, conduce siempre su paisaje" (Finlayson, 1938, p. 48) y revela el temperamento chileno. El poeta, cuando es verdaderamente grande, es expresión viva del temple de su pueblo, de su paisaje, de su clima y significa un abordaje de lo real característico en el que los pueblos se reconocen. Asimismo, en otro artículo, dedicado al poeta colombiano Porfirio Barba-Jacob, sostiene que "[...] los poetas han sido y todavía son los más genuinos representantes de la cultura nuestra" (Finlayson, 1946, p. 29). La universalidad de un pensamiento o de una expresión no tiene su origen en un trasmundo ajeno al propio:

[...] cuando un hombre se introspecta y marcha a sus raíces propias, cuando es sincero y capaz de manifestar su interior en aquello que de más hondamente único e individual tiene, entonces realiza una labor de universalidad en que coincide con toda la especie humana. (Finlayson, 1946, p. 23)

Neruda, el poeta telúrico, y Barba-Jacob, el poeta de lo humano individual, y muchos otros que Finlayson reseña son propiamente americanos y así lo revelan los matices propios de esta tierra: "[...] la poesía nace en América con perfiles propios distintos a los de la Península" (Finlayson, 1946, p. 29).

Europa habría tomado otro camino, el del desarrollo de la técnica (Caiceo, 2002, p. 191), y relega sus poetas y filósofos a meros adalides de ideologías. Por esto, se trataría, ahora, del inicio de un camino de retorno, ahora desde América, no solo para recuperar, sino incluso para salvar al ser humano de su propio poder. "Una civilización que se convierte en puramente técnica terminará por desaparecer” (Finlayson, 1969, p. 162), porque el poder no solo carece de suyo de una preorientación teleológica, sino porque en razón de su mismo autocentramiento, como solo se quiere a sí mismo y anhela su acrecentamiento, desprecia toda orientación y, si llega a tener alguna, pronto la abandona por otra y otra. 
Hoy estamos abocados como nunca en la historia a la amenaza de una destrucción de la estirpe humana; los descubrimientos científicos que culminaron en la bomba atómica y en la absoluta posibilidad de un arma aún más terrible, sea que se llame bomba de hidrógeno o reciba después otra denominación, cuando aún más se perfeccionen estos medios de destrucción, no dejan con razón de alarmar a los hombres conscientes. Se cree todavía - y creo que ingenuamente- que el peligro podrá detener a las naciones, o que una entidad negativa — temor a desaparecer de la faz del planeta- podrá realizar la unión de los hombres. No y mil veces no. Mientras no exista un ideal positivo esta unión será utópica y a la postre vendrá la destrucción. La actual era tiene carácter apocalíptico y catagénico. (Finlayson, 1953d, pp. 269-270)

Parecía, en ese momento, que Europa viniera huyendo de sí misma, incapaz de plantearse positivamente en la recuperación innovadora de sus tradiciones, desdeña lo humano, por meramente humano; pero sea que aspire a una pura vida instintiva, sea que aspire a su divinización, cada vez que el hombre se descentra de sí mismo, recuerda Finlayson citando a Aristóteles, hace en realidad de bestia. Finlayson está consciente de que aún no hay una filosofía genuinamente hispanoamericana que pueda realizar la recuperación del sentido de lo humano, perdido en una guerra en la que la deshumanización parece haber alcanzado a todos: "Sin embargo, hoy se está generando en nuestro continente un movimiento muy interesante que, aunque en los principios generales sea generado por movimientos europeos, en aspectos y en ciertas estructuras adquiere caracteres propios" (Finlayson, 1939, p. 220).

Esto propio a la vez que universal, para Finlayson, no es sino una forma de pensar y ser en la que el ser humano recupera el anclaje en la realidad, en el ser absoluto y en sí mismo como ser finito pero con vocación de infinito. De ahí que el título escogido para uno de sus libros en el que recoge diversos artículos, Hombre, mundo $y$ Dios, no sea solo una suerte de resumen de los temas tratados, sino un verdadero proyecto filosófico y vital. De este modo, para Finlayson, ha llegado el momento en que Latinoamérica desarrolle un pensamiento propio, pero también universal porque tiene una tarea fundamental en ese orden: "[1]a América se levanta hoy en la escena del mundo como una nueva interrogante estelar. La esperanza abre sus brazos sobre nuestros cielos infinitos" (Finlayson, 1945a, p. 99). 


\section{III}

La expresión "América, continente de la esperanza" de tan manida parece haberse convertido en una expresión irónica. Sin embargo, al hilo del pensamiento de Finlayson, se puede afirmar que esa esperanza fue siempre alimentada por los desvaríos de Europa y, precisamente por eso, cabe pensar que efectivamente América tuvo su oportunidad, la ha tenido. Efectivamente, Europa ha buscado en América desde el descubrimiento una recuperación de sí misma: gente viaja miles de kilómetros en condiciones que hoy parecen imposibles, con la esperanza, sí, de riqueza, de honores, de reconocimiento, pero también de construir una patria nueva, libre de persecución, de injusticia y de desamparo. Por otra parte, una Europa devastada o, incluso, más aún, seducida por ideologías antilibertarias, arrogantes e inhumanas, de lo cual la guerra no es sino una consecuencia, debía hacer pensar a América sobre su propio destino. Pero tal vez haya que repensar la expresión "continente de la esperanza", por cuanto la esperanza puede permanecer fiel a sí misma conservándose como tal.

El hombre sobrevive y soporta esta vida de peregrinaje fundamentad sobre la esperanza. La esperanza es la posibilidad hecha carne y vida dentro de la persona. Si la consideramos en su envergadura total, ella puede ser acogida dentro del mapa del ente. De allí que la esperanza pertenezca a la urdimbre ontológica del ser humano. (Finlayson, 1950).

Se podría pensar, entonces, que en la urdimbre del mapa del mundo, América es la esperanza que alienta a la recuperación de todo desvarío suicida de los seres humanos, como frontera siempre abierta, donde se puede reconstruir siempre una vida, por devastada que esté. Por esto, Finlayson sostiene que fue Unamuno “[...] el que hizo hincapié de cómo la esperanza era algo más que una superficie sentimental que nos acompañaba a la vera de nuestro destino: que era la trama metafísica, ontológica, de meridad tejidesca de nuestro propio ser en movimiento" (Finlayson, 1953c, p. 123). Porque el hombre, siempre en movimiento, encuentra en la esperanza la guía de su destino. 


\section{Referencias}

Caiceo Escudero, J. (2002). Clarence Finlayson: un esbozo de su pensamiento. Cuadernos de Filosofía Latinoamericana, (86-87), 181-191.

Escobar, R. (1986). Cuatro pensadores porteños. Atenea, 453-454, 335-343.

Finlayson, C. (1938). Paisaje en Pablo Neruda. Atenea, 54 (160), 47-60.

Finlayson, C. (1939). El movimiento filosófico en Chile. Revista de la Universidad Católica Bolivariana, 4(11-13), 220-221.

Finlayson, C. (1941). Academia Santo Tomás de Aquino de la Universidad Católica Bolivariana. Revista de la Universidad Católica Bolivariana, 7 (22), 321-235.

Finlayson, C. (1943). Recensión a 'Descubrimiento de América' de Waldo Frank. Revista de la Universidad Católica Bolivariana, 9 (32-33), 453-454.

Finlayson, C. (1945a). Expresión de la cultura americana. Revista de Indias, (73), 89-99.

Finlayson, C. (1945b). La filosofía en Argentina. Revista de la Universidad de Antioquia, (70), 327-332.

Finlayson, C. (1946). La poesía humana de Porfirio Barba-Jacob. Atenea 85 (253254), 16-46.

Finlayson, C. (1948). Los cronistas de Indias. Revista de Indias, (105), 407-414.

Finlayson, C. (1950, 18 de junio). La evolución del concepto de hombre. El Colombiano, Suplemento Literario.

Finlayson, C. (1953a). Espíritu y cultura de España. En Hombre, mundo y Dios (pp. 124-131). Bogotá: Editorial Cosmos.

Finlayson, C. (1953b). Francisco de Quevedo en los grandes temas del hombre. En Hombre, mundo y Dios (pp. 132-150). Bogotá: Editorial Cosmos.

Finlayson, C. (1953c). Muerte y vida breve en la literatura española. En Hombre, mundo y Dios (pp. 119-123). Bogotá: Editorial Cosmos,.

Finlayson, C. (1953d). La evolución homogénea de la idea de Dios. En Hombre, mundo y Dios (pp. 263-283). Bogotá: Editorial Cosmos. 
Finlayson, C. (1969). En torno a Spengler y a una filosofía de la historia. En Antología (pp. 157-173). Santiago: Editorial Andrés Bello.

Finlayson, C. (2006). La filosofía, disciplina esencial del hombre. En Escritos pensados (pp. 65-68). Santiago: Universidad Diego Portales.

Hanisch, W. (1969, 30 de noviembre). Revisión de Clarence Finlayson. El Mercurio.

Molina, E. (1953). La filosofía en Chile en la primera mitad del siglo Xx. Santiago: Editorial Nascimiento.

Sánchez de Irarrázabal, R. (1988). Clarence Finlayson Elliot (1913-1954). En J. Caiceo Escudero, y E. Sánchez de Irarrázabal, Sinopsis de la filosofía en Chile: textos, seminarios y ciclos de estudio (pp. 39-143). Santiago: Pontificia Universidad Católica de Chile. 